\title{
Neuropsychological profiles of adults with Klinefelter syndrome
}

\author{
KYLE BRAUER BOONE, ${ }^{1}$ RONALD S. SWERDLOFF, ${ }^{2}$ BRUCE L. MILLER, ${ }^{3}$ \\ DANIEL H. GESCHWIND, ${ }^{4}$ JILL RAZANI, ${ }^{1}$ ALISON LEE, ${ }^{1}$ IRENE GAW GONZALO,${ }^{2}$ \\ ANNA HADDAL, ${ }^{2}$ KATHERINE RANKIN, ${ }^{1}$ PO LU,${ }^{1}$ AND LYNN PAUL ${ }^{1}$ \\ ${ }^{1}$ Department of Psychiatry, Harbor-UCLA Medical Center \\ ${ }^{2}$ Department of Medicine (Endocrinology), Harbor-UCLA Medical Center \\ ${ }^{3}$ Department of Neurology, UCSF \\ ${ }^{4}$ Department of Neurology, UCLA
}

(Received September 27, 1999; Revised May 3, 2000; AcCePted May 4, 2000)

\begin{abstract}
Children and adolescents with Klinefelter syndrome (XXY) have been reported to show deficits in language processing including VIQ $<$ PIQ and a learning disability in reading and spelling. However, whether this is characteristic of adults with Klinefelter syndrome has not been established. Thirty-five men with Klinefelter syndrome, aged 16 to 61, and 22 controls were evaluated with a comprehensive neuropsychological battery. The Klinefelter patients scored significantly below controls in language skills, verbal processing speed, verbal and nonverbal executive abilities, and motor dexterity. Within the Klinefelter sample, three cognitive subgroups were identified: VIQ 7 or more points below PIQ $(n=10)$, VIQ within 6 points of PIQ $(n=12)$, and PIQ 7 or more points below VIQ $(n=12)$. The deficits detected in language, verbal processing speed, and verbal executive skills were found to be isolated to the VIQ < PIQ subgroup, while the abnormalities in motor dexterity and nonverbal executive skills were confined to the PIQ $<$ VIQ subgroup. Older age was significantly correlated with increases in VIQ relative to PIQ in the patient group, which suggests the intriguing possibility that the PIQ < VIQ subgroup primarily emerges in young adulthood, perhaps in response to the reported hormonal abnormalities detected in Klinefelter syndrome patients during puberty. (JINS, 2001, 7, 446-456)
\end{abstract}

Keywords: Klinefelter syndrome; 47,XXY; Sex chromosome abnormalities; Neuropsychological scores

\section{INTRODUCTION}

Klinefelter syndrome is a condition in which males are born with one or more extra $\mathrm{X}$ chromosomes. It is the most common sex chromosome disorder (Wesner et al., 1973) with a prevalence of approximately 1 in 500 to 800 phenotypic males (Jacobs, 1979; Maclean et al., 1961). The Klinefelter syndrome phenotype, as originally described, consists of a number of characteristics including small firm testes, infertility (azoospermia), varying degrees of impaired sexual maturation, gynecomastia and elevated gonadotropin levels (Klinefelter et al., 1942). Subsequent reports expanded the clinical manifestations of the disorder including recognition of cognitive and behavioral abnormalities (Hseah et al., 1978; Leonard et al., 1978; Paulsen et al., 1968; Robinson et al., 1979). Unfortunately, most of the empirical research

Reprint requests to: Kyle Brauer Boone, Ph.D., ABPP-ABCN, Box 495, Harbor-UCLA Medical Center, Department of Psychiatry, $1000 \mathrm{~W}$. Carson Street, F-9, Torrance, CA 90509-2910. E-mail: kboone@ rei.edu on the cognitive and behavioral disturbances are based on individual case reports or relatively small samples. In addition, the data that are available have generally been confined to children and adolescents, and have primarily focused on assessment of academic achievement and intellectual levels rather than a comprehensive investigation of multiple cognitive domains.

The presence of learning disabilities in reading and spelling in children and adolescents with Klinefelter syndrome have been widely reported (Annell et al., 1970; Bender et al., 1986, 1987, 1993; Funderburk \& Ferjo, 1978; Graham et al., 1988; Leonard, 1991; Mandoki et al., 1991; Nielsen, 1991; Nielsen et al., 1970; Pennington et al., 1982; Ratcliffe et al., 1991; Robinson et al., 1991a, 1991b; Rovet et al., 1995, 1996; Stewart et al., 1986, 1991; Walzer et al., 1986, 1991; Wesner et al., 1973) as well as collateral language disturbances in comprehension, expression, and verbal processing speed (Bender et al., 1983, 1987, 1989, 1993; Funderburk \& Ferjo, 1978; Graham et al., 1988; Haka-Ikse et al., 1978; Mandoki et al., 1991; Netley \& Rovet, 1982; Robinson et al., 
1986, 1991a; Rovet et al., 1996; Walzer et al., 1978, 1986, 1991). Evidence for disturbances in math ability is more equivocal with fewer publications documenting a deficit in this area (Nielsen, 1991; Rovet et al., 1995, 1996; Stewart et al., 1986, 1991; Wesner et al., 1973).

The majority of previous studies have suggested that VIQ is depressed relative to PIQ in children with Klinefelter syndrome (Graham et al., 1988; Netley, 1986; Netley \& Rovet, 1982, 1984, 1987; Nielsen et al., 1970; Pennington et al., 1982; Ratcliffe et al., 1982, 1986; Rovet et al., 1995, 1996; Stewart et al., 1986, 1991; Walzer et al., 1978, 1986, 1991). However, some reports have failed to confirm this observation (Bender et al., 1986; Funderburk \& Ferjo, 1978; Nielsen, 1991; Robinson et al., 1991b), and others have observed that while VIQ is usually lower than PIQ, occasionally this relationship is reversed (Annell et al., 1970; Ratcliffe et al., 1991; Robinson et al., 1991a).

Several studies have suggested that spatial abilities and spatial processing speed are spared in children with Klinefelter syndrome (Bender et al., 1986, 1989; Robinson et al., 1986, 1991b; Walzer et al., 1978). Isolated reports have pointed to possible deficits in attention (Rovet et al., 1996; Walzer et al., 1978), verbal memory (Bender et al., 1986, 1993), and visual perceptual skills (Wesner et al., 1973), but these conclusions await replication. The evidence for motor impairment has been equivocal, with some studies reporting deficits in motor function (Bender et al., 1987; Haka-Ikse et al., 1978) and others failing to detect any motor abnormality (Bender et al., 1993; Walzer et al., 1978). The single study investigating executive function in adolescents with Klinefelter syndrome found impairment on some tasks (i.e., Trailmaking Part B) but not others (i.e., Wisconsin Card Sorting Test; Bender et al., 1993).

The few, mostly small-sample, studies devoted to examination of adults with Klinefelter syndrome have observed a somewhat different pattern than that described above. Specifically, only minor and nonsignificant differences between Verbal and Performance IQ have been found (Barker \& Black, 1976; Money, 1964), with most subjects failing to show a significant lowering of VIQ relative to PIQ (Pasqualini et al., 1957; Theilgaard, 1986, 1990). There has been some evidence for difficulties in language (Porter et al., 1988), although memory (verbal and nonverbal) and verbal abstraction have been reported to be normal (Barker \& Black, 1976; Theilgaard, 1990). Performance on simple visual constructional tasks has also been observed to be intact (Barker \& Black, 1976; Serra et al., 1978), but with some deterioration in more complex visual spatial abilities (Nyborg \& Nielsen, 1981; Pasqualini et al., 1957; Porter et al., 1988; Theilgaard, 1990).

In conclusion, the available research appears to document the presence of a language processing disability in children and adolescents with Klinefelter syndrome. However, several questions remain. First, it is unclear whether additional cognitive abnormalities are present. Second, it has not been established whether the language impairment and other possible cognitive abnormalities in children and adolescents with Klinefelter syndrome continue to be present in adulthood or whether they normalize upon maturity. Finally, the discrepancies in the literature regarding VIQ versus PIQ differences raise the possibility of cognitive subtypes in Klinefelter syndrome, a hypothesis which has yet to be investigated.

The purpose of the present study was to determine (1) whether learning disabilities and/or other cognitive abnormalities exist in adults with Klinefelter syndrome, and (2) whether the Klinefelter syndrome population is cognitively homogenous or contains cognitively distinct subgroups.

\section{METHODS}

\section{Research Participants}

Thirty-five men with Klinefelter syndrome, ranging in age from 16 to 61 years, were studied. The participants were recruited from a group of patients either self- or physicianreferred to one of the investigators (RSS) for endocrinological assessment and management of hypogonadism and/or infertility. They were not specifically selected for behavioral or cognitive abnormalities. Data on hormone replacement treatment were available for 29 participants; 14 were on testosterone supplement while 15 were untreated.

Twenty-two male controls were recruited from the local community through newspaper and radio ads and flyers and were paid for their participation. Exclusion criteria included history of learning disability, major psychiatric disorder, substance abuse, or neurologic disorder.

All participants were fluent in English.

\section{Neuropsychological Battery}

Participants were administered a comprehensive 4-hr neuropsychological battery. The cognitive domains sampled, the tests used to assess the domains, and the specific test variables used for analysis, are detailed in Table 1.

The one unpublished test used in the study will be briefly described. The Word Sequencing Test, based on a similar task developed by Della Malva et al. (1993), consists of 20 scrambled sentences. The individual words for each sentence are placed in front of the patient in a standard scrambled order. The patient is instructed to create a sentence using all the words. Performance is timed with a limit of 120 s per sentence. All of the scrambled sentences include embedded overlearned word pairs; for half the sentences these word pairs must be uncoupled to correctly arrange the sentence. Two types of errors are scored: capture errors refer to failure to dissociate the overlearned word pairs, while noncapture errors refer to errors in sequencing unrelated to the overlearned word pairs. Test stimuli are reproduced in the Appendix.

We employed previously published procedures to reduce the number of test variables used in statistical analyses (Boone et al., 1995). Specifically, raw test scores were converted to standard equivalents (i.e., $z$ scores) using the test 
Table 1. Cognitive domains and associated tests

\begin{tabular}{|c|c|}
\hline Cognitive domain & Tests \\
\hline Intelligence-verbal & $\begin{array}{l}\text { Satz-Mogel format (Adams et al., 1984) for the Wechsler Adult Intelligence } \\
\text { Scale-Revised (WAIS-R; Wechsler, 1981); Verbal IQ }\end{array}$ \\
\hline Intelligence-nonverbal & Satz-Mogel format (Adams et al., 1984) for the WAIS-R Performance IQ \\
\hline Attention-verbal & Digit span raw score from the WAIS-R \\
\hline Information processing speed-verbal & $\begin{array}{l}\text { Stroop Test (Comalli version; Mitrushina et al., 1999; number of seconds to complete } \\
\text { Parts A and B) }\end{array}$ \\
\hline Information processing speed-nonverbal & $\begin{array}{l}\text { Trailmaking (Lezak, 1995; number of seconds to complete Part A); Digit Symbol raw } \\
\text { score from the WAIS-R }\end{array}$ \\
\hline Language & $\begin{array}{l}\text { Boston Naming Test (Kaplan et al., 1983; total correct out of 60); Word Sequencing } \\
\text { (noncapture errors; total of } 20 \text { possible); Wide Range Achievement Test-Revised } \\
\text { (WRAT-R; Jastak \& Wilkinson, 1984); Reading and Spelling raw scores }\end{array}$ \\
\hline Constructional ability & Copy of the Rey-Osterrieth Complex Figure (Lezak, 1995; total out of 36) \\
\hline Memory-verbal & $\begin{array}{l}\text { Logical Memory (LM) subtest of the Wechsler Memory Scale-Revised (WMS-R; } \\
\text { Wechsler, 1987; raw scores for immediate and delayed recall); Rey Auditory Verbal } \\
\text { Learning Test (AVLT; Lezak, 1995; scores for 5th learning trial, recall after interference, } \\
\text { 30-min delayed recall) }\end{array}$ \\
\hline Memory-nonverbal & $\begin{array}{l}\text { Visual Reproduction (VR) subtest of the WMS-R (raw scores for immediate and delayed } \\
\text { recall); 3-min delayed recall of the Rey-Osterrieth Complex Figure (Boone et al., 1993; } \\
\text { total score out of 36); Continuous Visual Memory Test (CVMT; Trahan \& Larrabee, 1988; } \\
\text { total score) }\end{array}$ \\
\hline Executive-verbal & $\begin{array}{l}\text { Stroop Test (Comalli version; Mitrushina et al., 1999; time in seconds to complete } \\
\text { Part C); Trailmaking (Lezak, 1995; time in seconds to complete Part B); Verbal Fluency } \\
\text { (FAS; Lezak, 1995; total words summed across three trials); Auditory Consonant Trigrams } \\
\text { (Mitrushina et al., 1999; total score out of 60); Word Sequencing (number of capture } \\
\text { errors; total possible of 10; see Appendix); AVLT (number of false positives on } \\
\text { recognition trial) }\end{array}$ \\
\hline Executive-nonverbal & $\begin{array}{l}\text { Wisconsin Card Sorting Test (WCST; Heaton, 1981; number of perseverative responses); } \\
\text { Design Fluency (Jones-Gotman \& Milner, 1977; total designs generated in } 5 \text { min); } \\
\text { Emotional Situations (Stuss \& Benson, 1983; number of errors); Rey Tangled Lines } \\
\text { (Lezak, 1976; } M \text { time per trial) }\end{array}$ \\
\hline Motor function & Grooved Pegboard (Lezak, 1995; $M$ time in seconds per hand) \\
\hline Arithmetic ability & Wide Range Achievement Test-Revised (WRAT-R) Arithmetic raw score \\
\hline
\end{tabular}

means and standard deviations from the control group. Test data were then collapsed into 13 summary scores by averaging each participant's $z$ scores on tests assessing the same functional domain.

\section{RESULTS}

As shown in Table 2, groups did not differ in age or educational level. The 13 summary neuropsychological measures were used as dependent variables in comparisons between patients and controls. The $p$ value used for determining significance was lowered to .01 as an adjustment for the multiple comparisons. Z-score means and standard deviations, and statistical values for the group comparisons, are reproduced in Table 2. Significant group differences were found for language, verbal information processing speed, verbal executive skills, nonverbal executive skills, and motor speed; no significant differences were observed for Verbal IQ, Performance IQ, constructional ability, verbal memory, verbal attention, nonverbal memory, math skills, or nonverbal information processing speed.
The sample was divided into three subgroupings based on VIQ versus PIQ profiles. Ten patients were found to have a VIQ which was at least a half a standard deviation or more below PIQ (i.e., 7 or more points). However, 12 patients displayed a PIQ that was 7 or more points lower than VIQ, and another 12 patients obtained VIQs within 6 points of PIQ. As shown in Table 3, ANOVAs comparing controls and the three patient subgroups were significant for the language, verbal information processing speed, and verbal executive domains, and nearly significant for the motor speed $(p=.02)$, verbal attention $(p=.03)$, and nonverbal executive $(p=.07)$ domains. Post-hoc analyses indicated that only the VIQ $<$ PIQ group scored significantly below controls on the language score $(p=.002)$, and this group also performed significantly lower than the PIQ $<$ VIQ group on this variable $(p=.018)$. Also, the VIQ $<$ PIQ group was the only group to significantly differ from controls on the verbal executive and verbal information processing speed scores ( $p=.004$ and .012 , respectively), and showed a nearly significant difference on the verbal attention score $(p=.10)$. In contrast, the PIQ $<$ VIQ group was the only 
Table 2. Group comparisons on demographic, IQ, and summary neuropsychological variables

\begin{tabular}{lccccc}
\hline \hline Variable & Patients & Controls & $t$ & $d f$ & $p$ \\
\hline Age (years) & $35.51 \pm 12.36$ & $34.32 \pm 14.81$ & .33 & 55 & .74 \\
Education (years) & $12.97 \pm 2.14$ & $13.36 \pm 2.15$ & -.67 & 55 & .50 \\
Intelligence & & & & \\
$\quad$ VIQ & $99.41 \pm 15.86$ & $106.46 \pm 17.01$ & -1.58 & 54 & .12 \\
$\quad$ PIQ & $98.26 \pm 14.60$ & $107.46 \pm 16.58$ & -2.20 & 55 & .03 \\
Verbal attention & $-.54 \pm 1.32$ & $.00 \pm 1.00$ & -1.64 & 53 & .11 \\
Language & $-.73 \pm 1.25$ & $.01 \pm .76$ & -2.62 & 53 & .01 \\
Spatial/constructional & $-.71 \pm 1.82$ & $.00 \pm 1.00$ & -1.68 & 55 & .10 \\
Info processing speed & & & & \\
$\quad$ Verbal & $-1.33 \pm 1.79$ & $.00 \pm .90$ & -3.72 & 55 & .0001 \\
$\quad$ Nonverbal & $-.53 \pm .74$ & $-.01 \pm .89$ & -2.23 & 55 & .03 \\
Memory & & & & \\
$\quad$ Verbal & $-.07 \pm .70$ & $.00 \pm .86$ & -.31 & 53 & .76 \\
$\quad$ Nonverbal & $-.09 \pm .92$ & $-.05 \pm .83$ & -.18 & 55 & .85 \\
Executive & & & & \\
$\quad$ Verbal & $-.85 \pm 1.00$ & $.00 \pm .63$ & -3.57 & 55 & .001 \\
$\quad$ Nonverbal & $-.54 \pm .93$ & $.01 \pm .71$ & -2.51 & 55 & .01 \\
Arithmetic & $-.22 \pm .76$ & $.00 \pm 1.00$ & -.89 & 49 & .38 \\
Motor speed & $-1.05 \pm 1.58$ & $.00 \pm .96$ & -2.61 & 49 & .01 \\
\hline
\end{tabular}

subgroup to differ significantly from controls on the composite motor score $(p=.05)$ and showed a trend toward a significant difference on the nonverbal executive score $(p=$ $.09)$.

To determine which specific tests within the language, verbal information processing speed, verbal executive, nonverbal executive, and motor speed domains were responsible for the group differences, comparisons between groups on the actual scores from the tests in these domains were computed. As shown in Table 3, significant group differences were documented for four of six verbal executive tests (ACT, AVLT false positives, word sequencing capture errors, and Stroop C), two of two verbal information processing speed tests (Stroop A and B), three of four language tests (reading raw score, spelling raw score, word sequencing noncapture errors), and one of two motor test scores (pegboard nondominant hand). When group comparisons were recomputed on pegboard scores omitting the 8 lefthanders and 1 ambidextrous participants ( 5 patients and 4 controls), a similar pattern (although no longer significant) was observed.

The performance of the three subgroups across the 11 non-IQ domains is profiled in Figure 1. The VIQ $<$ PIQ group scored lower on verbal domains (language, verbal attention, verbal executive, verbal information processing speed, verbal memory) relative to nonverbal domains (spatial/constructional, nonverbal memory, nonverbal executive, nonverbal information processing speed), while the PIQ $<$ VIQ group showed the opposite pattern as well as an impairment in motor speed. The VIQ = PIQ group displayed a mixed profile with lowest scores on motor functioning and verbal tasks.

While the three patient subgroups did not differ in age or education (see Table 3 ), it is of note that the mean age of the
PIQ $<$ VIQ group was more than 7 years older than the VIQ $<$ PIQ group, with the VIQ = PIQ group obtaining a mean age intermediate between the two other groups. Age was found to be significantly positively correlated with VIQ minus PIQ $(r=.414, p=.015)$.

Subgroup membership was tabulated for those patients on and off testosterone supplementation. Treated and untreated patients were fairly equally represented across the three IQ subtypes. Within the treated patients, 3 were in the VIQ $<$ PIQ subgroup, 3 were in the VIQ = PIQ subgroup, and 8 were in the PIQ $<$ VIQ subgroup. In the untreated group, 4 were in the VIQ $<$ PIQ group, 7 were in the $\mathrm{VIQ}=\mathrm{PIQ}$ group, and 4 were in the PIQ $<$ VIQ group. Treated and untreated patients did not differ in age $[t(27)=$ $1.17, p=.252]$, education $[t(27)=-.42, p=.680]$, Full Scale IQ $[t(27)=.89, p=.383$; VIQ: $t(27)=1.15, p=$ .259 ; PIQ: $[t(27)=.42, p=.677]$.

\section{DISCUSSION}

Comprehensive testing of 35 men with Klinefelter syndrome aged 16 to 61 revealed evidence for the group as a whole of a language processing abnormality including a learning disability involving reading and spelling. In addition, mild deficits were also observed in verbal information processing speed, motor dexterity, and verbal and nonverbal executive problem-solving skills. In contrast, memory skills (verbal and nonverbal), verbal attention, visualspatial/constructional skill, math competence, nonverbal information processing speed, and IQ scores did not differ significantly from controls.

Closer analysis revealed that subgroups could be identified based on Verbal IQ versus Performance IQ discrepancies. Tabulation of VIQ versus PIQ patterns in the current 
Table 3. Mean neuropsychological scores for controls and patient subgroups

\begin{tabular}{|c|c|c|c|c|c|c|}
\hline \multirow[b]{2}{*}{ Variable } & \multirow[b]{2}{*}{$\begin{array}{l}\text { Controls } \\
(n=22)\end{array}$} & \multicolumn{3}{|c|}{ Patients } & \multirow[b]{2}{*}{$F$} & \multirow[b]{2}{*}{$p$} \\
\hline & & $\begin{array}{c}\mathrm{VIQ}<\mathrm{PIQ} \\
(n=10)\end{array}$ & $\begin{array}{c}\mathrm{VIQ}=\mathrm{PIQ} \\
(n=12)\end{array}$ & $\begin{array}{c}\mathrm{PIQ}<\mathrm{VIQ} \\
(n=12)\end{array}$ & & \\
\hline Age & $34.32 \pm 14.81$ & $31.20 \pm 14.34$ & $33.75 \pm 9.92$ & $38.58 \pm 10.29$ & .63 & .599 \\
\hline Education & $13.36 \pm 2.15$ & $12.00 \pm 2.63$ & $13.42 \pm 1.78$ & $13.25 \pm 2.01$ & 1.10 & .358 \\
\hline \multicolumn{7}{|l|}{ IQ } \\
\hline FSIQ & $107.14 \pm 15.89$ & $100.00 \pm 15.49$ & $95.25 \pm 14.61$ & $101.25 \pm 14.67$ & 1.67 & .185 \\
\hline VIQ & $106.46 \pm 17.01$ & $92.60 \pm 14.10$ & $95.33 \pm 13.41$ & $109.17 \pm 15.75$ & 3.40 & $.024^{*}$ \\
\hline PIQ & $107.46 \pm 16.58$ & $110.40 \pm 14.31$ & $95.67 \pm 13.29$ & $91.33 \pm 10.79$ & 5.13 & $.003 *$ \\
\hline VERB. ATTENT. Summary Score & $0 \pm 1.00$ & $-1.13 \pm 1.01$ & $-.72 \pm 1.35$ & $.11 \pm 1.33$ & 3.21 & .031 \\
\hline Digit Span (raw score) & $16.14 \pm 4.10$ & $11.50 \pm 4.14$ & $13.18 \pm 5.55$ & $16.58 \pm 5.44$ & 3.21 & .031 \\
\hline LANGUAGE Summary Score & $0 \pm-.76$ & $-1.52 \pm 1.60$ & $-.72 \pm .94$ & $0 \pm .85$ & 6.33 & $.001 * a, b$ \\
\hline Boston Naming & $54.71 \pm 5.60$ & $50.10 \pm 6.86$ & $53.42 \pm 3.90$ & $54.75 \pm 4.54$ & 1.94 & .134 \\
\hline \multicolumn{7}{|l|}{ WRAT-R } \\
\hline Reading (raw) & $69.47 \pm 10.29$ & $53.00 \pm 14.00$ & $56.83 \pm 13.84$ & $69.60 \pm 13.75$ & 5.42 & $.003 * \mathrm{a}$ \\
\hline Spelling (raw) & $34.21 \pm 8.11$ & $25.00 \pm 10.05$ & $26.42 \pm 11.02$ & $34.56 \pm 10.66$ & 3.12 & $.035^{*}$ \\
\hline \multicolumn{7}{|l|}{ Word Sequencing } \\
\hline Noncapture errors & $.26 \pm .56$ & $2.00 \pm 2.55$ & $.17 \pm .41$ & $.42 \pm .52$ & 4.67 & $.007 * \mathrm{a}, \mathrm{b}, \mathrm{c}$ \\
\hline SPATIAL Summary Score & $0 \pm 1.00$ & $-.58 \pm 1.60$ & $-.23 \pm 1.21$ & $-1.17 \pm 2.43$ & 1.57 & .208 \\
\hline Rey copy & $34.18 \pm 2.22$ & $32.90 \pm 3.54$ & $33.67 \pm 2.67$ & $31.58 \pm 5.40$ & 1.57 & .208 \\
\hline \multicolumn{7}{|c|}{ INFORMATION PROCESSING SPEED } \\
\hline Verbal Summary Score & $0 \pm .90$ & $-1.96 \pm 1.92$ & $-1.48 \pm 1.99$ & $-.57 \pm 1.35$ & 5.14 & $.003 * \mathrm{a}$ \\
\hline Stroop A & $43.64 \pm 8.16$ & $57.90 \pm 13.87$ & $53.67 \pm 13.64$ & $47.75 \pm 14.28$ & 3.98 & $.013 * \mathrm{a}$ \\
\hline Stroop B & $58.91 \pm 9.96$ & $80.50 \pm 21.49$ & $75.64 \pm 25.96$ & $65.33 \pm 11.11$ & 4.86 & $.005 * \mathrm{a}$ \\
\hline Nonverbal Summary Score & $0 \pm .89$ & $-.37 \pm .86$ & $-.37 \pm .68$ & $-.76 \pm .69$ & 2.09 & .112 \\
\hline Trails A & $25.32 \pm 10.18$ & $29.10 \pm 8.85$ & $27.92 \pm 5.95$ & $33.75 \pm 8.53$ & 2.31 & .088 \\
\hline Digit Symbol (raw score) & $56.36 \pm 15.00$ & $50.90 \pm 14.58$ & $47.73 \pm 14.26$ & $46.00 \pm 9.37$ & 1.84 & .151 \\
\hline \multicolumn{7}{|l|}{ MEMORY } \\
\hline Verbal Summary Score & $0 \pm .86$ & $-.25 \pm .56$ & $0 \pm .74$ & $0 \pm .79$ & .32 & .813 \\
\hline \multicolumn{7}{|l|}{ AVLT } \\
\hline Trial 5 & $12.00 \pm 2.45$ & $11.10 \pm 2.28$ & $11.42 \pm 1.88$ & $12.17 \pm 2.29$ & .58 & .632 \\
\hline Trial 7 & $10.29 \pm 3.21$ & $10.00 \pm 2.87$ & $10.00 \pm 3.08$ & $10.42 \pm 3.55$ & .05 & .984 \\
\hline Trial 8 & $10.24 \pm 3.83$ & $10.00 \pm 3.56$ & $10.08 \pm 2.81$ & $10.17 \pm 3.93$ & .01 & .998 \\
\hline Logical Memory I & $23.67 \pm 6.92$ & $20.30 \pm 7.55$ & $24.42 \pm 7.48$ & $23.75 \pm 6.65$ & .73 & .541 \\
\hline Logical Memory II & $20.00 \pm 9.09$ & $17.70 \pm 6.70$ & $21.33 \pm 8.57$ & $21.08 \pm 7.50$ & .43 & .734 \\
\hline Nonverbal Summary Score & $0 \pm .83$ & $0 \pm 1.07$ & $.11 \pm .63$ & $-.31 \pm .98$ & .57 & .636 \\
\hline CVMT Total & $77.58 \pm 8.64$ & $78.38 \pm 9.35$ & $77.92 \pm 6.36$ & $76.92 \pm 8.67$ & .06 & .982 \\
\hline Rey delay & $21.91 \pm 6.47$ & $23.90 \pm 5.67$ & $24.13 \pm 4.65$ & $19.92 \pm 7.77$ & 1.15 & .338 \\
\hline Visual Reproduction I & $36.00 \pm 3.72$ & $34.10 \pm 7.59$ & $35.50 \pm 3.48$ & $33.42 \pm 5.27$ & .86 & .469 \\
\hline Visual Reproduction II & $27.85 \pm 7.85$ & $30.00 \pm 8.54$ & $29.33 \pm 5.68$ & $26.58 \pm 9.31$ & .43 & .731 \\
\hline \multicolumn{7}{|l|}{ EXECUTIVE } \\
\hline Verbal Summary Score & $0 \pm .63$ & $-1.28 \pm 1.23$ & $-.84 \pm 1.00$ & $-.48 \pm .73$ & 5.78 & $.002 * \mathrm{a}$ \\
\hline Consonant Trigrams & $46.86 \pm 6.73$ & $38.13 \pm 11.22$ & $44.08 \pm 8.33$ & $48.33 \pm 8.87$ & 2.86 & $.046^{*}$ \\
\hline AVLT false positives & $.74 \pm 1.10$ & $2.40 \pm 2.63$ & $.92 \pm 1.31$ & $1.33 \pm 1.07$ & 2.77 & $.05^{*}$ \\
\hline \multicolumn{7}{|l|}{ Word Sequencing } \\
\hline Capture errors & $.74 \pm .87$ & $2.60 \pm 2.68$ & $2.33 \pm 2.61$ & $1.17 \pm 1.59$ & 2.96 & $.041^{*}$ \\
\hline Verbal Fluency & $38.32 \pm 9.73$ & $34.30 \pm 8.19$ & $30.50 \pm 10.58$ & $36.50 \pm 10.43$ & 1.73 & .172 \\
\hline Stroop C & $112.36 \pm 21.48$ & $146.10 \pm 41.74$ & $142.46 \pm 46.95$ & $136.92 \pm 24.98$ & 3.67 & $.018^{*}$ \\
\hline Trails B & $62.53 \pm 22.42$ & $75.00 \pm 34.65$ & $70.83 \pm 24.47$ & $78.67 \pm 38.39$ & .85 & .475 \\
\hline Nonverbal Summary Score & $0 \pm .71$ & $-.28 \pm 1.07$ & $-.47 \pm .71$ & $-.76 \pm 1.04$ & 2.47 & .072 \\
\hline Design Fluency & $29.00 \pm 15.14$ & $25.60 \pm 21.26$ & $27.67 \pm 9.74$ & $25.42 \pm 11.98$ & .20 & .898 \\
\hline Emotion Situations & $.68 \pm 1.06$ & $1.40 \pm .55$ & $1.33 \pm 1.12$ & $1.08 \pm 1.17$ & 1.12 & .353 \\
\hline Tangled Lines & $7.73 \pm 2.07$ & $7.82 \pm 3.13$ & $8.99 \pm 2.53$ & $9.76 \pm 3.07$ & 1.86 & .149 \\
\hline WCST persev. respons. & $14.23 \pm 12.16$ & $19.22 \pm 15.38$ & $22.83 \pm 15.13$ & $31.50 \pm 32.95$ & 2.09 & .113 \\
\hline ARITHMETIC Summary Score & $0 \pm 1.00$ & $-.37 \pm .80$ & $-.20 \pm .76$ & $-.13 \pm .78$ & .39 & .760 \\
\hline \multicolumn{7}{|l|}{ WRAT-R } \\
\hline Arithmetic (raw) & $36.74 \pm 10.10$ & $33.00 \pm 8.12$ & $34.75 \pm 7.68$ & $35.46 \pm 7.83$ & .39 & .760 \\
\hline MOTOR Summary Score & $0 \pm .96$ & $-.27 \pm .95$ & $-1.11 \pm 1.63$ & $-1.48 \pm 1.81$ & 3.46 & .02 \\
\hline \multicolumn{7}{|l|}{ Pegboard } \\
\hline Dominant & $71.95 \pm 16.15$ & $73.71 \pm 12.98$ & $82.04 \pm 16.45$ & $89.50 \pm 26.33$ & 2.42 & .078 \\
\hline Nondominant & $76.00 \pm 13.05$ & $81.57 \pm 17.33$ & $96.71 \pm 33.01$ & $100.33 \pm 26.77$ & 3.57 & $.021 * \mathrm{~d}$ \\
\hline Dominant* & $72.73 \pm 17.69$ & $73.71 \pm 12.98$ & $77.50 \pm 10.53$ & $85.30 \pm 23.95$ & 1.14 & .345 \\
\hline Nondominant* & $76.67 \pm 12.81$ & $81.57 \pm 17.34$ & $91.60 \pm 33.92$ & $96.80 \pm 25.56$ & 1.82 & .160 \\
\hline
\end{tabular}

Note. Patient $n$ only equals 34 because 1 patient did not have VIQ data and could not be assigned to a VIQ/PIQ group.

*left-handers excluded.

$\mathrm{a}=\mathrm{VIQ}<$ PIQ group significantly lower than controls.

$\mathrm{b}=\mathrm{VIQ}<$ PIQ group significantly lower than PIQ $<$ VIQ group.

$\mathrm{c}=\mathrm{VIQ}<$ PIQ group significantly lower than VIQ $=$ PIQ group.

$\mathrm{d}=$ PIQ $<$ VIQ group significantly lower than controls. 


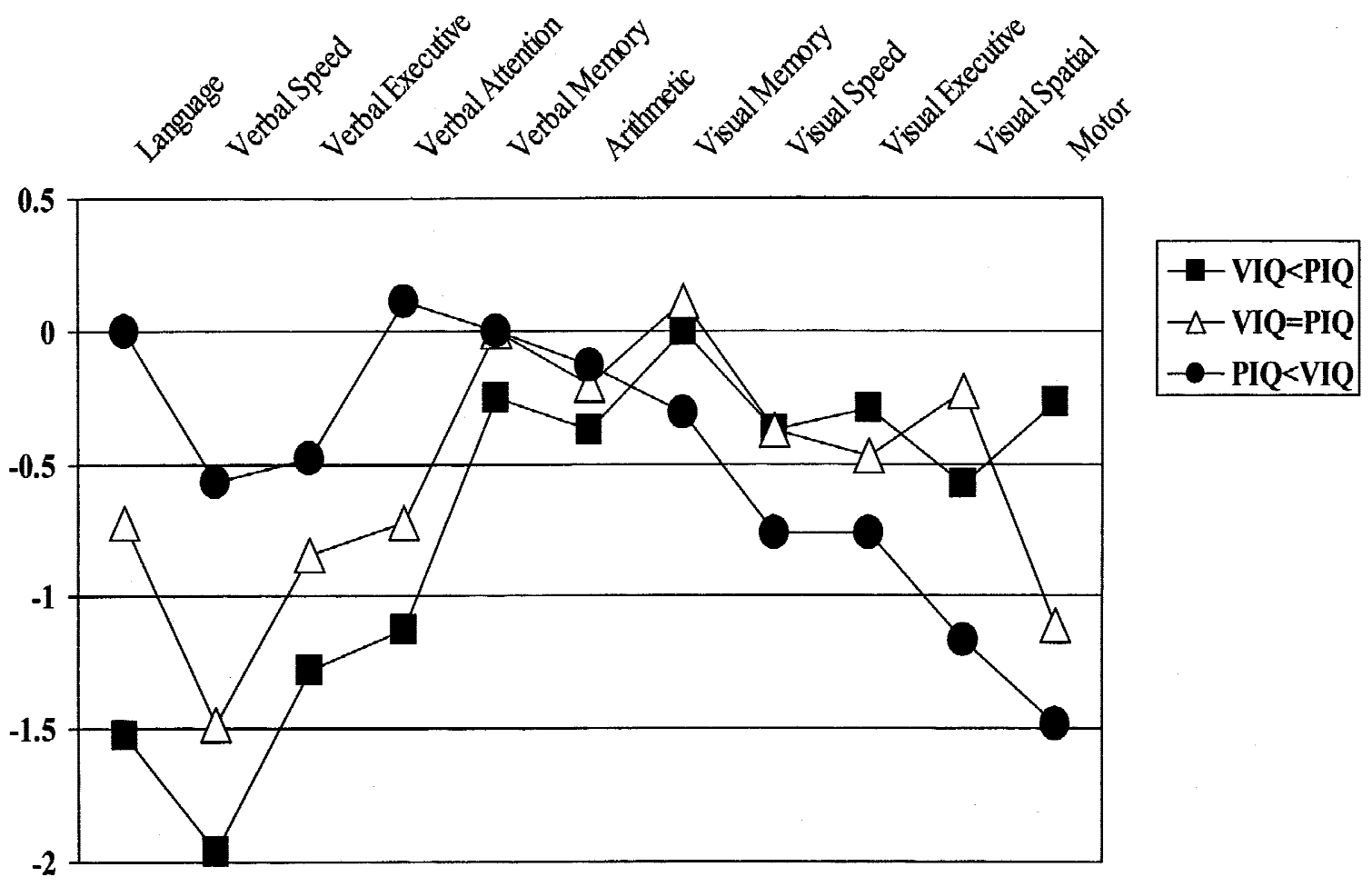

Fig. 1. Cognitive patterns in Klinefelter subgroups.

sample revealed that nearly one-third obtained VIQs which were at least one-half standard deviation below PIQs (i.e., lower by 7 or more points), while another third showed the reverse pattern, and the final third achieved VIQs that were essentially equal to PIQ (within 6 points). Further analyses indicated that the language (including reading and spelling), verbal information processing speed, and verbal executive abnormalities detected in the patient group as a whole were actually confined to the VIQ < PIQ subsample. In contrast, the impairment in motor speed and lowered nonverbal executive ability was isolated to the PIQ $<$ VIQ group.

Rankings of performance from best to worst across the various cognitive domains for each subgroup revealed that the VIQ < PIQ and PIQ < VIQ groups displayed nearly a mirror opposite pattern of scores. Specifically, the VIQ $<$ PIQ group performed within the average range on measures of visual spatial skill, nonverbal memory, nonverbal information processing speed, nonverbal executive, motor function, arithmetic, and verbal memory, but scored within the low average range on measures of verbal attention and verbal executive ability. Language performance and verbal information processing speed were particularly depressed and fell within the borderline impaired range. In contrast, the PIQ < VIQ subgroup performed within the average range in the domains of language, verbal information processing speed, verbal memory, verbal attention, visual memory, verbal executive ability, and arithmetic, but within the low average range for visual-spatial/constructional ability, nonverbal information processing speed, and nonverbal ex- ecutive skills. Borderline impaired scores were obtained for motor dexterity. The VIQ = PIQ group showed a mixed pattern with particularly low scores observed for verbal information processing speed and motor dexterity.

The VIQ < PIQ subgroup, with its primary language abnormality, shows a cognitive profile consistent with left hemisphere dysfunction, while the PIQ < VIQ subgroup, with its deficits in visual spatial skills, displays a pattern consistent with right hemisphere disturbance. In this light it is important to note that the motor impairment which was isolated to the PIQ $<$ VIQ group was primarily driven by abnormalities in left hand performance. Given that the right hemisphere controls left hand dexterity, these data add additional support to the conclusion that the PIQ $<$ VIQ group appears to have a primary right hemisphere abnormality. The VIQ = PIQ group displays a mixed cognitive pattern consistent with mild disturbance of both hemispheres.

Collateral weaknesses in language and verbal skills are typically found in patients with VIQ $<$ PIQ, while patients with PIQ < VIQ usually show lowered performance on visual-spatial and motor dexterity tasks (Korkman \& Pesonen, 1994; Zillmer et al., 1991). Thus, the fact that the VIQ/PIQ subgroups displayed diverse cognitive profiles is not surprising. What is unexpected is that a PIQ $<$ VIQ subgroup exists in the adult Klinefelter population in numbers apparently equal to that of the VIQ $<$ PIQ group.

The observation that only one-third of our sample had VIQs 7 or more points below PIQ, while fully another third of our sample had PIQs 7 or more points below VIQ, does not mesh with previous literature on younger individuals 
showing that most display a depressed VIQ. Walzer et al. (1978), in examining 8 children with Klinefelter syndrome aged 5 to 7, reported that all obtained a PIQ greater than VIQ, with the discrepancies ranging from 9 to 26 points with an average of nearly 18 points. In the age group 6 to 8 , 12 of 13 had a VIQ at least 7 points below PIQ, with 1 child showing a VIQ equal to PIQ (Walzer et al., 1986). Between the ages of 9 and 12, 10 of these 13 children had a VIQ at least 7 points below PIQ, while 3 had VIQ and PIQ within 6 points of each other (Walzer et al., 1991). Ratcliffe et al. (1986), examining Klinefelter syndrome boys aged 6 to 8, observed higher PIQs ( $\geq 7$ points) in 7 of 12 patients, with higher VIQs in 3 children and relatively equal VIQs and PIQs (within 6 points) in 2 patients. By age 7 to 12 , most had VIQ $<$ PIQ $(n=11)$, but 4 had Verbal IQs at least 12 points higher than PIQ (Ratcliffe et al., 1991). Rovet et al. (1996) observed that between 86 and $93 \%$ of their sample of boys tested from ages 6-8 to 18-20 had a VIQ which was more than 1 standard deviation below PIQ.

One intriguing possibility for the discrepancy between our data and previous studies is that the PIQ < VIQ subgroup primarily emerges in adulthood. In support of this hypothesis, data from the current study reveal that the PIQ $<$ VIQ group averaged 7 years older than the VIQ $<$ PIQ group, and increasing age was associated with a rise in VIQ relative to PIQ. The meager literature on intellectual functioning in Klinefelter syndrome patients between the ages of 18 and 50 has revealed only minimal differences (i.e., 2-5 points) between Verbal and Performance IQs (Barker \& Black, 1976; Pasqualini et al., 1957), a finding which would be expected if equal-sized VIQ < PIQ and PIQ < VIQ subgroups were collapsed. Also of note, Stewart et al. (1991) reported in their longitudinal testing of Klinefelter syndrome patients that by age 17, PIQs had fallen and the VIQ $<$ PIQ discrepancy was not as pronounced. They conclude: "Changes in the relative levels of these intellectual skills may occur during the course of development ... the degree of verbal/nonverbal discrepancy may diminish primarily because of small decreases in PIQ as maturation proceeds" (p. 165). Similarly, examination of the Rovet et al. (1995) longitudinal data also shows that VIQ remained relatively stable over time, although at age $18-20$, PIQ suddenly dropped an average of 7.2 points (from 99.8 at age $15-17$ to 92.8 at $18-20$ ).

Finally, Netley and Rovet (1984), using dichotic listening tasks, initially found that prepubertal Klinefelter syndrome males showed reduced left hemisphere specialization for verbal tasks and enhanced right hemisphere specialization for nonverbal tasks. However, these abnormalities had completely normalized after puberty, leading the investigators to raise the possibility that "hemispheric organization changed between the first assessment at age a mean of 11.3 years and the second at a mean age of 16 years" (Stewart et al., 1991, p. 166).

Taken as a whole, the literature would suggest that there are two separate processes at work which impact on the cognitive profile seen in Klinefelter syndrome: an early lan- guage abnormality related to developmental left hemisphere dysfunction, followed by the emergence of a weakness in visual spatial skills associated with right hemisphere disturbance which appears primarily in young adulthood in a subset of Klinefelter syndrome males. The finding that our adult subgroup with VIQ > PIQ had language scores which are identical with controls suggests that when the visual spatial deficit emerges, the language deficit normalizes.

The early abnormal functioning of the left hemisphere in Klinefelter syndrome is thought to be related to developmental slowing in the rate of cell division prenatally (Netley \& Rovet, 1987) as illustrated by smaller head circumference (Funderburk \& Ferjo, 1978; Graham et al., 1988; Ratcliffe et al., 1986, 1991; Stewart et al., 1986, 1991) and reduced total finger ridge count observed in this population (Netley $\&$ Rovet, 1987). Slowed development has been found to consistently impact verbal skills, with bone age maturation and total finger ridge count inversely related to verbal skills in Klinefelter syndrome (Netley \& Rovet, 1982, 1987; Stewart et al., 1982). The slowed development is thought to differentially retard the growth of the left hemisphere, allowing the right hemisphere to develop without the normal inhibitory influences of the left hemisphere (Stewart et al., 1986). The cause of the slowed development has been hypothesized to be due to excessive androgenic activity (Geschwind \& Galaburda, 1987). Klinefelter syndrome infants do not display a surplus of androgen, but they may have a higher sensitivity to androgen or an increase in the density of androgen receptors (Levy \& Heller, 1992).

The question arises as to what mechanism would explain a decrement in PIQ/nonverbal skills and left hand dexterity, as well as an improvement in VIQ and collateral verbal skills, which emerges in young adulthood. One possibility is that the hormonal abnormalities detected at puberty in Klinefelter syndrome, including low testosterone level (Ratcliffe et al., 1982; Salbenblatt et al., 1985; Schiavi et al., 1978; Wang et al., 1975) in combination with normal or high levels of estradiol (Forti et al., 1978), and enhanced conversion of testosterone to estradiol (Garbrilove et al., 1980), not only cause the gynecomastia observed in approximately one-third of postpubertal Klinefelter syndrome males (Winter, 1991), but also lead to a feminization of the brain. With advancing age, Klinefelter syndrome patients register a further decline in testosterone production, which results in a further increase in estradiol:testosterone ratios (Garbrilove et al., 1979).

Depletion of androgen or blocking of its actions may disrupt right hemisphere function (Levy \& Heller, 1992) and is associated with declines in visual-spatial functioning (Collaer \& Hines, 1995; Levy \& Heller, 1992), while estrogen enhances verbal skills (Lindman et al., 1998). Men with idiopathic hypogonadotropic hypogonadism and associated low androgen levels, as well as men with Kwashiorkor, a disorder in which estrogens accumulate due to abnormalities in liver metabolism, obtain Performance IQs substantially lower than Verbal IQs (Collaer \& Hines, 1995; Levy \& Heller, 1992). It is also relevant to note that spatial 
ability of human females declines post puberty, and spatial ability is lowest in women during the estrogen-high phase of the menstrual cycle (Nyborg \& Nielsen, 1981). Similarly, in animal studies, female rats show a decline in spatial skills post puberty, and spatial abilities of male rats have been found to be lowered with estrogen treatment ( Nyborg \& Nielsen, 1981).

Nyborg and Nielsen (1981) have posited an "optimal estrogen level" theory in which it is proposed that "spatial ability is coded for by genes on autosomal chromosomes, the expression of which are related to plasma hormone concentrations" (p. 97). Estrogen is conceptualized as the major influence in spatial ability with testosterone serving to modulate the effect of estrogen. Intermediate levels of estrogen maximize spatial ability, while estrogen levels too low or too high interfere with this skill. Women, given their high estrogen levels, display lowered spatial ability, and similarly, men with surges in estrogen level, such as feminized men with Kwashiorkor syndrome and feminized 46,XY men insensitive to their own testosterone, also show lowered spatial skills. With respect to Klinefelter syndrome, Nyborg and Nielsen (1981) conclude:

Abnormally low concentration of plasma testosterone (or perhaps abnormal hormonal metabolism) results in physical feminization of men with Klinefelter syndrome, transgression of the level of estrogen optimal for the full expression of spatial ability, and suppression of the autosomal gene for this trait. (pp. 98-99)

In summary, the shift from prepubertal hyperandrogenic activity to postpubertal hypoandrogenic activity could explain the presence of early language impairment in Klinefelter syndrome, which is followed by a subsequent decline in right hemisphere skills in at least a subset of Klinefelter syndrome males in late adolescence and young adulthood.

The question arises as to why the 14 participants on testosterone supplementation in the current study did not consistently register VIQ < PIQ; in fact, most of them $(n=8)$ displayed a PIQ which was at least 7 points less than VIQ. The impact of sex hormones in Klinefelter syndrome appears to be a highly complex phenomenon as evidenced by the fact that patients with and without gynecomastia show no difference in serum testosterone and estradiol levels (Robinson et al., 1991b). Testosterone treatment may actually produce an increase in serum estradiol levels due to aromatization of administered hormone and will produce a negative feedback effect on pituitary LH and FSH secretion, resulting in decreased testicular production of testosterone (Winter, 1991). The biologic effects of testosterone on various body tissues may differ due to a number of factors including relative concentrations of metabolyzing enzymes (aromatase and 5 alpha reductase) and androgen and estrogen receptors. Thus, testosterone effects on some target organs (e.g., muscles) may be predominantly mediated through androgen receptors, while in other organs (e.g., brain and bone) its effects may in part be mediated through estrogen receptors and in part through androgen receptors (Wang \&
Swerdloff, 1999). Finally, emerging evidence suggests the effect of testosterone on spatial performance is an inverted $U$-shape rather than linear, with high and low levels of testosterone associated with decreased ability (Erlanger et al., 1999). As a result of these various factors, the impact of testosterone treatment on cognition in Klinefelter syndrome is not necessarily straightforward or predictable. In addition, in the current study, duration and age of onset of treatment and dosage were not standardized which may have obscured the influence of treatment on cognitive scores. The impact of testosterone on cognition in Klinefelter syndrome could be examined by longitudinal study of never treated adolescents administered either standardized hormone replacement or placebo.

The evidence for a dysexecutive syndrome in Klinefelter syndrome could help account for the behavioral abnormalities, including poor judgment, impulsivity, failure to consider consequences of one's behavior, and deficits in social skills, often observed in this population. However, not all Klinefelter syndrome patients display behavioral difficulties, and we suspect that the subgroup with lowered nonverbal executive abilities (i.e., the PIQ $<$ VIQ group), may have more social difficulties given previous reports of more prominent behavioral impairments in right-hemisphere as compared to left-hemisphere disorders (Miller et al., 1993). However, confirmation of this hypothesis awaits future research.

There are several limitations to the present study. First, although we could discern no obvious selection bias in our patients, it is possible that men with Klinefelter syndrome seeking treatment for hypogonadism and/or infertility differ in some respects from the larger Klinefelter population. Secondly, the identification of VIQ/PIQ subgroups was determined by cut-points applied on a range of VIQ-minusPIQ differences scores. While this created groups for statistical comparisons and allowed for a richer description of our Klinefelter sample, it should be emphasized that these subgroups reside on a continuum and may not represent truly distinct entities.

All of our Klinefelter syndrome patients were diagnosed at puberty or older with treatment not commencing until that time. The recent emergence of prenatal genetic testing allows for intrauterine diagnosis of Klinefelter syndrome and earlier testosterone replacement. Whether early hormonal treatment will alter the cognitive profile in future cohorts of men with Klinefelter syndrome awaits further research.

\section{REFERENCES}

Adams, R.L., Smigielski, J., \& Jenkins, R.L. (1984). Development of a Satz-Mogel short form of the WAIS-R. Journal of Consulting and Clinical Psychology, 52, 908.

Annell, A., Gustavson, K., \& Tenstam, J. (1970). Symptomatology in schoolboys with positive sex chromatin (The Klinefelter Syndrome). Acta Psychiatrica Scandinavica, 46, 71-80.

Barker, T.E. \& Black, F.W. (1976). Klinefelter syndrome in a military population. Archives of General Psychiatry, 33, 607-610. 
Bender, B., Fry, E., Pennington, B., Puck, M., Salbenblatt, J., \& Robinson, A. (1983). Speech and language development in 41 children with sex chromosome anomalies. Pediatrics, 71, 262-267.

Bender, B., Linden, M., \& Robinson, A. (1987). Environment and developmental risk in children with sex chromosome abnormalities. Journal of the American Academy of Child Psychiatry, 26, 499-503.

Bender, B., Linden, M., \& Robinson, A. (1989). Verbal and spatial processing efficiency in 32 children with sex chromosome abnormalities. Pediatric Research, 25, 577-579.

Bender, B., Linden, M., \& Robinson, A. (1993). Neuropsychological impairment in 42 adolescents with sex chromosome abnormalities. American Journal of Medical Genetics (Neuropsychiatric Genetics), 48, 169-173.

Bender, B.G., Puck, M.H., Salbenblatt, J.A., \& Robinson, A. (1986). Dyslexia in 47,XXY boys identified at birth. Behavior Genetics, 16, 343-354.

Boone, K.B., Lesser, I.M., Hill-Gutierrez, E., Berman, N., \& D'Elia, L. (1993). Rey-Osterrieth Complex Figure performance in healthy, older adults: Relationship to age, education, sex, and IQ. Clinical Neuropsychologist, 7, 22-28.

Boone, K.B., Lesser, I.M., Miller, B.L., Wohl, M., Berman, N., Lee, A., Palmer, B., \& Back, C. (1995). Cognitive functioning in older depressed outpatients: Relationship of presence and severity of depression to neuropsychological scores. Neuropsychology, 9, 390-398.

Collaer, M.L. \& Hines, M. (1995). Human behavioral sex differences: A role for gonadal hormones during early development? Psychological Bulletin, 118, 55-107.

Della Malva, C.L., Stuss, D.T., D’Alton, J., \& Willmer, J. (1993). Capture errors and sequencing after frontal brain lesions. Neuropsychologia, 31, 363-372.

Erlanger, D.M., Kuthner, K.C., \& Jacobs, A.R. (1999). Hormones and cognition: Current concepts and issues in neuropsychology. Neuropsychology Review, 9, 175-207.

Forti, G., Giusti, G., Borghi, A., Pazzagli, M., Fiorelli, G., Cabresi, E., Mannelli, M., Bassi, F., Gianotti, P., Fusi, S., \& Serio, M. (1978). Klinefelter's syndrome: A study of its hormonal plasma pattern. Journal of Endocrinological Investigation, 2, 149-154.

Funderburk, S.J. \& Ferjo, N. (1978). Clinical observations in Klinefelter (47,XXY) syndrome. Journal of Mental Deficiency Research, 22, 207-212.

Garbrilove, J.L., Freiberg, E.K., Thornton, J.C., \& Nicolis, G.L. (1979). Effect of age on testicular function in patients with Klinefelter's syndrome. Clinical Endocrinology, 11, 343-347.

Garbrilove, J.L., Freibert, E.K., \& Nicolis, G.L. (1980). Testicular function in Klinefelter's syndrome. Journal of Urology, 124, 825-826.

Geschwind, N. \& Galaburda, A.M. (1987). Cerebral lateralization: Biological mechanisms, associations, and pathology. Cambridge, MA: The MIT Press.

Graham, J., Bashir, A., Stark, R., Silbert, A., \& Walzer, S. (1988). Oral and written language abilities of XXY boys: Implications for anticipatory guidance. Pediatrics, 81, 795-806.

Haka-Ikse, K., Stewart, D.A., \& Cripps, M.H. (1978). Early development of children with sex chromosome aberrations. $\mathrm{Pe}$ diatrics, 62, 761-766.

Heaton, R.K. (1981). Wisconsin Card Sorting Test. Odessa, FL: Psychological Assessment Resources.

Hseah, W.A., Hsu, T.H., \& Federman, D.D. (1978). Endocrine features of Klinefelter's syndrome. Medicine, 57, 447-461.
Jacobs, P.A. (1979). The incidence and etiology of sex chromosome abnormalities in man. Birth Defects, 15, 3-14.

Jastak, S. \& Wilkinson, G.S. (1984). Wide Range Achievement Test-Revised. Wilmington, DE: Jastak Assessment Systems.

Jones-Gotman, M. \& Milner, B. (1977). Design fluency: The invention of nonsense drawings after focal cortical lesions. Neuropsychologia, 15, 653-674.

Kaplan, E.F., Goodglass, H., \& Weintraub, S. (1983). The Boston Naming Test (2nd ed.). Philadelphia: Lea \& Febiger.

Klinefelter, H.F., Jr., Reifenstein, E.C., Jr., \& Albright, F. (1942). Syndrome characterized by gynecomastia, aspermatogenesis without a-Leydigism and increased excretion of folliclestimulation hormone. Journal of Clinical Endocrinology and Metabolism, 2, 615-627.

Korkman, M. \& Pesonen, A. (1994). A comparison of neuropsychological test profiles of children with attention deficithyperactivity disorder and/or learning disorder. Journal of Learning Disabilities, 27, 383-392.

Leonard, M.F. (1991). A prospective study of development of children with sex chromosome anomalies: New Haven Study. V. Young Adulthood. Birth Defects, 26, 117-130.

Leonard, J.M., Paulsen, C.A., Ospena, L.F., \& Burgess, E.C. (1978). The classification of Klinefelter's Syndrome. In H.L. Vallet \& I.H. Porter (Eds.), Genetic mechanisms of sexual development (pp. 407-423). New York: Academic Press.

Levy, J. \& Heller, W. (1992). Gender differences in human neuropsychological function. In A.A. Gerall, H. Moltz, \& I.L. Ward (Eds.), Sexual differentiation, Volume 11. Handbook of behavioral neurobiology (pp. 245-272). New York: Plenum Press.

Lezak, M.D. (1976). Neuropsychological assessment. New York: Oxford University Press.

Lezak, M.D. (1995). Neuropsychological assessment (3rd ed.). New York: Oxford University Press.

Lindman, K., Boone, K., Lesser, I., \& Miller, B. (1998, February). Does estrogen replacement therapy protect cognitive ability in postmenopausal women? Poster presented at the International Neuropsychological Society Meeting, Honolulu, HI.

MacLean, J., Harnden, D.G., \& CourtBrown, W.M. (1961). Abnormalities of sex chromosome constitution in newborn babies. Lancet 2, 7199, 406.

Mandoki, M.W., Sumner, G.S., Hoffman, R.P., \& Riconda, D.L. (1991). A review of Klinefelter's syndrome in children and adolescents. Journal of the American Academy of Child and Adolescent Psychiatry, 30, 167-172.

Miller, B.L., Chang, L. Mena, I., Boone, K., Lesser, I.M. (1993). Progressive right frontotemporal degeneration: Clinical, neuropsychological and SPECT characteristics. Dementia, 4, 204-213.

Mitrushina, M.N., Boone, K.B., \& D’Elia, L.F. (1999). Handbook of normative data for neuropsychological assessment. New York: Oxford University Press.

Money, J. (1964). Two cytogenetic syndromes: Psychologic comparisons 1. Intelligence and specific-factor quotients. Journal of Psychiatic Research, 2, 223-231.

Netley, C. (1986). Summary overview of behavioural development in individuals with neonatally identified $\mathrm{X}$ and $\mathrm{Y}$ aneuploidy. Birth Defects, 22, 293-306.

Netley, C. \& Rovet, J. (1982). Verbal deficits in children with 47,XXY and 47,XXX karyotypes: A descriptive and experimental study. Brain and Cognition, 17, 58-72.

Netley, C. \& Rovet, J. (1984). Hemispheric lateralization in 47,XXY Klinefelter syndrome boys. Brain and Cognition, 3, 10-18. 
Netley, C. \& Rovet, J. (1987). Relations between a dermatoglyphic measure of hemispheric specialization and intellectual abilities in 47,XXY males. Brain and Cognition, 6, 153-160.

Nielsen, J. (1991). Follow-up of 25 unselected children with sex chromosome abnormalities to age 12. Birth Defects: Original Articles Series, 26, 201-207.

Nielsen, J., Bjarnason, S., Friedrich, U., Froland, A., Hansen, V., \& Sorensen, A. (1970). Klinefelter's syndrome in children. Journal of Child Psychology and Psychiatry, 11, 109-119.

Nyborg, H. \& Nielsen, J. (1981). Spatial ability of men with karyotype 47,XXY or normal controls. In W. Schmid \& J. Nielsen (Eds.), Human behavior and genetics (pp. 85-106). Amsterdam: Elsevier/North-Holland.

Pasqualini, R.Q., Vidal, G., \& Bur, G.E. (1957). Psychopathology of Klinefelter's syndrome. Lancet 2, 6487, 164-167.

Paulsen, C.A., Gordon, D.L., Carpenter, R.W., Grandy, H.M., \& Drucker, W.D. (1968). Klinefelter's syndrome and its variants: A hormonal and chromosomal study. Recent Progress in Hormone Research, 24, 321-363.

Pennington, B., Bender, B., Puck, M., Salbenblatt, J., \& Robinson, A. (1982). Learning disabilities in children with sex chromosome anomalies. Child Development, 53, 1182-1192.

Porter, M.E., Gardner, H.A, DeFeudis, P., \& Endler, N.S. (1988). Verbal deficits in Klinefelter (XXY) adults living in the community. Clinical Genetics, 33, 246-253.

Ratcliffe, S., Bancroft, J., Axworthy, D., \& McLaren, W. (1982). Klinefelter's syndrome in adolescence. Archives of Diseases of Childhood, 57, 6-12.

Ratcliffe, S.G., Butler, G.E., \& Jones, M. (1991). Edinburgh study of growth and development of children with sex chromosome abnormalities. IV. Birth Defects: Original Article Series, 26, 1-44.

Ratcliffe, S.G., Murray, L., \& Teague, P. (1986). Edinburgh study of growth and development of children with sex chromosome abnormalities III. Birth Defects: Original Article Series, 22, 73-118.

Robinson, A., Bender, B.G., Borelli, J.B., Puck, M.H., Salbenblatt, J.A., \& Winter, J.S.D. (1986). Sex chromosomal aneuploidy: Prospective and longitudinal studies. Birth Defects: Original Article Series, 22, 23-71.

Robinson, A., Bender, B.G., \& Linden, M.G. (1991a). Summary of clinical findings in children and young adults with sex chromosome anomalies. Birth Defects: Original Article Series, 26, 225-228.

Robinson, A., Bender, B.G., Linden, M.G., \& Salbenblatt, J.A. (1991b). Sex chromosome aneuploidy: The Denver prospective study. Birth Defects: Original Article Series, 26, 59-115.

Robinson, A., Lubs, H.A., Bergsma, D. (1979). Summary of clinical findings: Profiles of children with 47XXY, 47XXX karyotypes. Birth Defects, 15, 261-281.

Rovet, J., Netley, C., Bailey, J., Keenan, M, \& Stewart, D. (1995). Intelligence and achievement in children with extra $\mathrm{X}$ aneuploidy: A longitudinal perspective. American Journal of Medical Genetics (Neuropsychiatric Genetics), 60, 356-363.

Rovet, J., Netley, C., Keenan, M., Bailey, J., \& Stewart, D. (1996). The psychoeducational profile of boys with Klinefelter Syndrome. Journal of Learning Disabilities, 29, 180-196.

Salbenblatt, J.A., Bender, B.G., Puck, M.H., Robinson, A., \& Winter, J.S. (1985). Pituitary-gonadal function in Klinefelter syndrome before and during puberty. Pediatric Research, 19, 82-86.

Schiavi, R.C., Owen, D., Fogel, M., White, D., Szechter, R. (1978). Pituitary-gonadal function in XYY and XXY men identified in a population survey. Clinical Endocrinology (Oxf), 9, 233-239.
Serra, A., Pizzamiglio, L., Boari, A., \& Spera, S. (1978). A comparative study of cognitive traits in human sex chromosome aneuploids and sterile and fertile euploids. Behavior Genetics, 8, 143-154.

Stewart, D.A., Bailey, J.D., Netley, C.T., \& Park, E. (1991). Growth, development, and behavioral outcome from mid-adolescence to adulthood in subjects with chromosome aneuploidy: The Toronto Study. Birth Defects, 26, 131-188.

Stewart, D.A., Bailey, J.D., Netley, C.T., Rovet, J., \& Park, E. (1986). Growth and development from early to midadolescence of children with $\mathrm{X}$ and $\mathrm{Y}$ chromosome aneuploidy: The Toronto Study. Birth Defects, 22, 119-182.

Stewart, D.A., Bailey, J.D., Netley, C.T., Rovet, J., Park, E., Cripps, M., \& Curtis, J.S. (1982). Growth and development of children with $\mathrm{X}$ and $\mathrm{Y}$ chromosome aneuploidy from infancy to pubertal age: The Toronto Study. Birth Defects: Original Article Series, 18, 99-154.

Stuss, D.T. \& Benson, D.F. (1983). Emotional concomitants of psychosurgery. In K. Heilman \& P. Satz (Eds.), Neuropsychology of human emotion (pp. 111-140). New York: Guilford Press.

Theilgaard, A. (1986). Psychologic study of XYY and XXY men. Birth Defects: Original Article Series, 22, 277-292.

Theilgaard, A. (1990). Men with sex chromosome aberrations-as subjects and human beings. In D.B. Berch \& B.G. Bender (Eds.), Sex chromosome abnormalities and human behavior (pp. 145160). Boulder, CO: Westview Press.

Trahan, D.E. \& Larrabee, G.J. (1988). Continuous Visual Memory Test. Odessa, FL: Psychological Assessment Resources.

Walzer, S., Bashir, A.S., Graham, J.M., Silbert, A.R., Lange, N.T., DeNapoli, M.F., \& Richmond, J.B. (1986). Behavioral development of boys with $\mathrm{X}$ chromosome aneuploidy: Impact of reactive style on the educational intervention for learning deficits. Birth Defects: Original Article Series, 22, 1-21.

Walzer, S., Bashir, A.S., \& Silbert, A.R. (1991). Cognitive and behavioral factors in the learning disabilities of $47, \mathrm{XXY}$ and 47,XYY boys. Birth Defects, 26, 45-58.

Walzer, S., Wolff, P.H., Bowen, D., Silbert, A.R., Bashir, A.S., Gerald, P.S., \& Richmond, J. (1978). A method for the longitudinal study of behavioral development: the early development of XXY children. Journal of Child Psychology and Psychiatry, 19, 213-229.

Wang, C., Baker, H.W.G., Burger, H.G., DeKnetsen, D.M., \& Hudson, B. (1975). Hormone studies in Klinefelter's syndrome. Clinical Endocrinology, 4, 399-411.

Wang, C. \& Swerdloff, R.S. (1999). Androgen replacement therapy: Risks and benefits. In C. Wang (Ed.), Male reproductive function, (pp. 157-172). Norwell, MA: Kluwer Academic Publishers.

Wechsler, D. (1981). Wechsler Adult Intelligence Scale-Revised manual. New York: The Psychological Corporation.

Wechsler, D. (1987). Wechsler Memory Scale-Revised manual. San Antonio, TX: The Psychological Corporation.

Wesner, C.E., Spangler, P., Petrides, A., Baker, D., \& Telfer, M.A. (1973). Prepubertal Klinefelter Syndrome: A report of six cases. Journal of Mental Deficiency Research, 17, 237-246.

Winter, J.S.D. (1991). Androgen therapy in Klinefelter syndrome during adolescence. Birth Defects, 26, 235-245.

Zillmer, E.A., Ball, J.D., Fowler, P.C., \& Newman, A.C. (1991). Wechsler Verbal-Performance IQ discrepancies among psychiatric inpatients: Implications for subtle neuropsychological dysfunctioning. Archives of Clinical Neuropsychology, 6 , 61-71. 


\section{APPENDIX}

\section{WORD SEQUENCING}

\section{Instructions}

Individual word cards for each sentence are placed in front of the patient in the following scrambled order. Patients are instructed to arrange the words to make sentences using all cards. Patients are allowed up to $120 \mathrm{~s}$ to complete each sentence. Correct sentence orders are shown below the scrambled orders. Items 3, 5, 6, 8, 10, 11,14, 16, 18, and 19 contain word pairs that must be uncoupled to correctly arrange the sentences. Failure to uncouple results in a capture error; 10 capture errors are possible. An error in sequencing not involving the overlearned word pair is referred to as a noncapture error; 20 noncapture errors are possible.

1. orange juice he all the drank of (He drank all of the orange juice)

2. we around parking lot walked the (We walked around the parking lot)

3. the from fell the rain clouds (The rain fell from the clouds)

4. clothes the used to she buy credit card (She used the credit card to buy clothes)

5. went air plane the through the (The plane went through the air)

6. put he wrist watch on the his (He put the watch on his wrist)
7. bus stop at waited the they (They waited at the bus stop)

8. stop light the at will we (We will stop at the light)

9. was purse her in key chain the [The (her) key chain was in her (the) purse]

10. to fire engine the went the (The engine went to the fire)

11. in poured she the coffee cup (She poured coffee in the сир)

12. around fastened seat belt her she the (She fastened the seat belt around her)

13. the he hammer the found tool box in (He found the hammer in the tool box)

14. pony tail the its moved (The pony moved its tail)

15. toll booth the put she in money (She put money in the toll booth)

16. we a club sandwich ate the at (We ate a sandwich at the club) or (At the club we ate a sandwich)

17. ate they birthday cake the (They ate the birthday cake)

18. wrote on a the note pad she (She wrote a note on the pad)

19. fruit cake ate we the and the [We ate the fruit (cake) and the cake (fruit)]

20. the in eggs frying pan cooked she (She cooked eggs in the frying pan) 